\title{
Short communication: Genetic analysis for fertility traits of heifers and cows from smallholder dairy farms in a tropical environment
}

\author{
S. Buaban, ${ }^{* 1}$ M. Duangjinda,† M. Suzuki,§ Y. Masuda,§ J. Sanpote, ${ }^{*}$ and K. Kuchidał \\ ${ }^{*}$ The Bureau of Biotechnology in Livestock Production, Department of Livestock Development, Pratumtani 12000, Thailand \\ †Department of Animal Science, Khon Kaen University, Meaung, Khon Kaen 40002, Thailand \\ †Department of Animal and Food Hygiene, and \\ $\S$ Department of Life Science and Agriculture, Obihiro University of Agriculture and Veterinary Medicine, Inada-cho, Obihiro, Hokkaido 080-8555, \\ Japan
}

\section{ABSTRACT}

The objective of this study was to estimate genetic parameters for various fertility traits on Holstein upgraded dairy heifers and cows in a smallholder system under tropical conditions using data sets from the Thailand national recording scheme. The investigated traits were age at first service (AFS), age at first calving (AFC), days from calving to first service (DTFS), days between first and last service (DFLS), days open (DO), calving interval (CI), number of services per conception (NSPC), and conception at first service (FSC). The data consisted of $68,555,34,401$, and 54,004 records on heifers, primiparous, and multiparous cows, respectively, calving between 1996 and 2011. Gibbs sampling was employed to obtain (co)variance components using both univariate and bivariate analyses with linear and threshold animal models. Virgin heifers had better fertility performance than primiparous and multiparous cows. The reproductive performance in primiparous cows was inferior compared with multiparous cows. Cows with higher Holstein-Friesian blood showed lower reproductive efficiency. Estimated heritabilities for most of the fertility traits were 0.04 or less except for AFS (0.26) and AFC (0.25). The estimated genetic correlations among fertility traits within parity indicated that selection for cows with high conception rate could lead to shortened DO and CI, as well as DTFS. The FSC and NSPC could be used as the best indicators for heifer and cow fertility and could be complemented by other traits, which were genetically considered as different traits such as DTFS and DFLS in terms of a fertility index. This would enable efficient selection for better fertility. Genetic correlations for fertility traits in primiparous and multiparous cows were very high $(>0.90)$, but those between heifers and cows were lower (0.03 to 0.83$)$. The latter results indicated that fertility

Received September 17, 2014.

Accepted March 27, 2015.

${ }^{1}$ Corresponding author: buaban_ai@hotmail.com traits of heifers and cows should be considered as different traits.

Key words: Holstein upgraded, genetic parameters, reproduction, tropics

\section{Short Communication}

Demand for dairy products is rapidly growing in Asia, Africa, and Latin America, induced by urbanization and preferences for nutritious foods (Guyomard et al., 2013). Typical dairy system in these regions is based on low-input, smallholder farming in a tropical environment. An increase of milk production is expected to supply the demand as well as to raise the income of dairy farmers. Genetic improvement of the dairy cattle, along with changing feeding practices, is shown to greatly increase milk production (McDermott et al., 2010). Crossbreeding of local breeds with temperate dairy breeds, such as Holstein-Friesian (HF), has been recommended to achieve both high productivity and resistance to heat stress (Philipsson, 2000). However, cattle with high proportions of exotic temperate blood tend to be managed intensively. Additionally, these exotic breeds are by definition not well adapted to the local climate, feed resources, and management systems and require some level of environmental modification (such as cooling and ventilation system) to remain reasonably healthy and productive (Herath and Mohammad, 2009).

Thailand, as a tropical country, is located between $5^{\circ} 35^{\prime}$ and $20^{\circ} 30^{\prime} \mathrm{N}$ and $97^{\circ} 20^{\prime}$ and $105^{\circ} 40^{\prime}$ E. Annual temperatures typically range from 19 to $38^{\circ} \mathrm{C}$ (66 to $100^{\circ} \mathrm{F}$ ), relative humidity ranges from 66 to $81 \%$, and rainfall ranges from 201 to $2724 \mathrm{~mm}$. Thailand has 3 seasons: summer (March-June), rainy season (JulyOctober), and winter (November-February; Meteorological Department, 2013). The dairy cattle population reported in 2013 consisted of 512,205 animals with 229,899 cows on 17,094 farms (Department of Livestock Development, 2014), and raw milk production was approximately 1,067,452 $\mathrm{t}$ per year (Office of Agricultural 
Economics, 2014). The majority of dairy farmers (80\%) are smallholders with an average of 30 animals per farm (calves, heifers, and cows). Most of the dairy cows are crossbred from Bos indicus, such as Sahiwal, Brahman, and Thai Native cattle upgraded by HF. Currently, the majority of the dairy population has $>75 \% \mathrm{HF}$ blood. Average milk yield per cow is $4,000 \mathrm{~kg}$ per lactation. Generally, no cooling devices are available in the barns. More than $90 \%$ of dairy cattle are subjected to AI services provided by a government organization (Department of Livestock Development, Thailand), and the rest are serviced by a semi-government organization (Dairy Promotion Organization, Thailand) and the dairy cooperatives in the areas. Frozen semen used for AI services is both imported and produced locally. The AI records of dairy cattle have been collected in the database system by AI technicians since 1996. The daily feed ration is based heavily on concentrates. Roughages commonly used consist of tropical grass, rice straw, and some agricultural wastes. The ingredient composition of the concentrate feed depends on local availability and price. However, shortages of roughage are serious in winter and summer, and farmers have to buy hay or rice straw or increase their use of commercial mixed rations.

The dairy cattle in Thailand have been developed through the national sire selection and AI mating program since 1956, focusing on milk production. Continuous increasing milk yield by selection has induced a decrease in reproductive performance (Pryce and Veerkamp, 2001) due to the antagonistic genetic relationship between milk yield and fertility traits (Roxstrom et al., 2001; Liu et al., 2008). In particular, during early lactation in high-yielding cows, dietary intake of cows fails to keep pace with the demand for peak milk production (Bauman and Currie, 1980), leading to negative energy balance, which has serious consequences on other body functions (Banos et al., 2006; Løvendahl et al., 2010). The inclusion of fertility in the breeding goal is necessary to optimize the result of genetic improvement of dairy cattle.

The reproductive performance of dairy cows under smallholder conditions in Thailand from 2001 to 2005 was studied and reported by Leelasiri et al. (2006). The averages of days from calving to first service (DTFS, d), days between first and last service (DFLS, d), days open $(\mathbf{D O}, \mathrm{d})$, number of services per conception (NSPC, no.), and calving interval (CI, d) were 86.50 $\pm 0.12,23.33 \pm 0.02,127.99 \pm 0.23,1.89 \pm 0.00$, and $410.14 \pm 0.23$, respectively. Research on genetic studies of fertility traits in tropical conditions, including Thailand, is very limited, but data sets are available from a few herds (e.g., Demeke et al., 2004; König et al., 2005; Estrada-León et al., 2008).
The objective of this study was to estimate genetic parameters for various fertility traits on crossbred dairy heifers and cows in a smallholder system under tropical conditions, using AI data from the national recording scheme.

Data of pedigrees, breeding records, calving information, and lactation information of Thai dairy cattle, calving between 1996 and 2011, were obtained from the dairy cattle database of the Bureau of Biotechnology for Livestock Production, Department of Livestock Development, Thailand. The investigated traits were age at first service (AFS, mo), age at first calving (AFC, mo), DTFS, DFLS, DO, CI, NSPC, and conception at first service (FSC). The NSPC and FSC were considered as ordered categorical and binary traits, whereas the DTFS, DFLS, DO, and CI were determined as continuous traits (time interval traits). The traits recorded from birth to first calving were considered as heifer traits. Traits measured on first-lactation animals were considered as primiparous cow traits, and the traits measured from second to fifth lactation were considered as multiparous cow traits. Therefore, AFS and AFC were considered as specific traits for heifers, whereas DTFS, DO, and CI were considered as specific cow traits. The DFLS, FSC, and NSPC were defined for both heifers and cows. A conception for a heifer or a cow in a specific parity was determined with subsequent calving data that got along with the latest insemination data. A subsequent service within $10 \mathrm{~d}$ from previous insemination was considered a double insemination, and was discarded. Animals with complete records were included in the analysis if at least one contemporary mate was present in a herd-year of first service subclass for heifers, and a herd-year of calving subclass for cows. The sires for heifers and cows in the data set were identified.

The final edited data sets for univariate analyses and bivariate analyses within parity included 68,555 , 34,401 , and 54,004 fertility records for 68,555 heifers, 34,401 primiparous cows, and 34,400 multiparous cows (1.57 records per cow), respectively. The data of primiparous cows were fewer than heifers in this population because some farmers have limited capacities such as land and funds, so they sold the pregnant heifers to other farms that are not under the Department of Livestock Development database system. For bivariate analyses across parity, the data sets consisted of 20,433 , 16,986 , and 16,107 animals for heifers-primiparous cows, heifers-multiparous cows, and primiparous-multiparous cows, respectively. For univariate and bivariate analyses within parity, the pedigree records were constructed by tracing 3 generations of ancestors, and $131,689,72,624$, and 67,887 heifers, primiparous cows, and multiparous cows, respectively, were found. In ad- 
dition, the pedigree records of bivariate analyses across parity for heifers-primiparous cows, heifers-multiparous cows, and primiparous-multiparous cows were 47,413, 38,606 , and 37,434 animals, respectively.

The univariate analyses with linear and threshold animal model were performed for Gaussian and categorical traits, according to the following models, which were applied from Abe et al. (2009) and Tiezzi et al. (2012):

$$
\mathbf{y}=\mathbf{X} \boldsymbol{\beta}+\mathbf{Z}_{\mathrm{hy}} \mathbf{h y}+\mathbf{Z}_{\mathrm{a}} \mathbf{a}+\mathbf{Z}_{\mathrm{ss}} \mathrm{ss}+\mathbf{e}
$$

for heifers and primiparous cows, and

$$
\mathbf{y}=\mathbf{X} \boldsymbol{\beta}+\mathbf{Z}_{\mathrm{hy}} \mathbf{h y}+\mathbf{Z}_{\mathrm{a}} \mathbf{a}+\mathbf{Z}_{\mathrm{p}} \mathbf{p}+\mathbf{Z}_{\mathrm{ss}} \mathrm{ss}+\mathbf{e}
$$

for multiparous cows, where $\mathbf{y}$ is a vector of observations for linear traits (AFS, AFC, DTFS, DFLS, DO, and $\mathrm{CI}$ ) or a vector of unobserved liabilities for categorical traits (NSPC and FSC); $\boldsymbol{\beta}$ is a vector of systematic effects; hy $\sim N\left(0, \mathbf{I} \sigma_{h y}^{2}\right)$ is a vector of contemporary group (CG) effects, defined as the herd-year of first service effects for heifer traits and herd-year of calving effects for cow traits; $\mathbf{a} \sim N\left(0, \mathbf{A} \sigma_{a}^{2}\right)$ is a vector of additive genetic effects for all animals in the pedigree; $\mathbf{p} \sim N\left(0, \mathbf{I} \sigma_{p}^{2}\right)$ is a vector of permanent environmental effects for all animals with records (only multiparous cows); ss $\sim N\left(0, \mathbf{I} \sigma_{s s}^{2}\right)$ is a vector of service sire effects (only for FSC); $\mathbf{e} \sim N\left(0, \mathbf{I} \sigma_{e}^{2}\right)$ is a vector of residual effects; $\mathbf{X}$ is the incidence matrix for fixed effects; $\mathbf{Z}_{\mathrm{hy}}$, $\mathbf{Z}_{\mathrm{a}}, \mathbf{Z}_{\mathrm{p}}$, and $\mathbf{Z}_{\mathrm{ss}}$ are the incidence matrices for random effects; $\mathbf{A}$ is the additive relationships matrix among animals; $\mathbf{I}$ is the identity matrix; $\sigma_{h y}^{2}, \sigma_{a}^{2}, \sigma_{p}^{2}, \sigma_{s s}^{2}$, and $\sigma_{e}^{2}$ are herd-year, additive genetic, permanent environment, service sire, and residual variances, respectively. The following systematic effects were considered: breed group (4 classes) and year-month of first service (185 classes) for AFS and AFC in heifers; breed group (4 classes), AFS (5 classes), and year-month of first service (185 classes) for DFLS, FSC, and NSPC in heifers; breed group (4 classes), age at calving (7 classes), and year-month of calving (181 classes) for all traits in primiparous and multiparous cows. Effect of parity (4 classes) was also considered for multiparous cows. The effect of inseminator/AI technician was not considered because only one inseminator/AI technician was assigned to be responsible for one AI unit. Hence, this factor was completely accounted for by the management group effect (only one technician within a herdyear or year-month).
Bivariate analyses were used to investigate the genetic relationship among different fertility traits within parity and between the same fertility traits across parity fitting linear-linear, threshold-linear, and threshold-threshold animal models. For within-parity analysis, only animals that had records for both traits were used. For across parity analysis, only animals that had records for both parities were used. The identical model to the univariate approach was assumed for each trait except analyses of AFC and the other heifer traits (NSPC, FSC, and DFLS) where AFS was not included in the model.

Estimates of (co)variance components from both univariate and bivariate analyses were calculated by a Bayesian implementation via Gibbs sampling. Computations were carried out using the program THRGIBBS1F90 (Tsuruta and Misztal, 2006). The total length of the Gibbs chain was 250,000 cycles with the first 50,000 cycles used as the burn-in period, which were determined based on visual inspection of trace plots of selected (co)variance components. Thinning interval was set to 20 , and the resulting 10,000 samples were used to calculate posterior means and standard deviations. Posterior means were used as a point estimate of the (co)variance components for calculation heritabilities $\left(\mathrm{h}^{2}\right)$, herd contributions $\left(\mathrm{c}^{2}\right)$, genetic correlations $\left(r_{g}\right)$, and phenotypic correlations $\left(r_{p}\right)$.

Table 1 shows least squares means of various fertility traits in different parities and breed groups. The mean AFS and AFC were 22.9 and 32.9 mo. The FSC of heifers was 16.7 and $15.2 \%$ higher than that of primiparous and multiparous cows, respectively, whereas NSPC and DFLS of heifers were 0.57 services and $20.9 \mathrm{~d}$ less than primiparous cows and 0.49 services and $17.6 \mathrm{~d}$ less than multiparous cows. Moreover, the tendency of all traits in the multiparous cows was better than those in the primiparous cows. Generally, reproductive efficiency in heifers and cows trended to be lower as HF blood increased. The breed group with $\geq 93.75 \%$ HF had the lowest reproductive performance.

The mean of AFS was higher than $499.7 \pm 53.6 \mathrm{~d}$ (16.7 mo) reported in Canadian Holsteins (Jamrozik et al., 2005), $518.6 \pm 84.8 \mathrm{~d}(17.3 \mathrm{mo})$ in Japanese Holsteins (Abe et al., 2009), $482.4 \pm 40.87$ d (16.1 mo) in Iranian Holsteins (Eghbalsaied, 2011), and 519.8 $\pm 51.1 \mathrm{~d}(17.3 \mathrm{mo})$ in Chinese Holsteins (Guo et al., 2014). The longer AFS in Thai dairy cattle could be due to the environmental condition, particularly feeding level. It is generally recognized that dairy heifers in tropical areas have a lower growth rate than those in temperate areas (Vaccaro and Rivero, 1985). The FSC, NSPC, and DFLS in heifers were better than in primiparous and multiparous cows because they were 
Table 1. Least squares means (SE) of fertility traits in different parities and breed groups

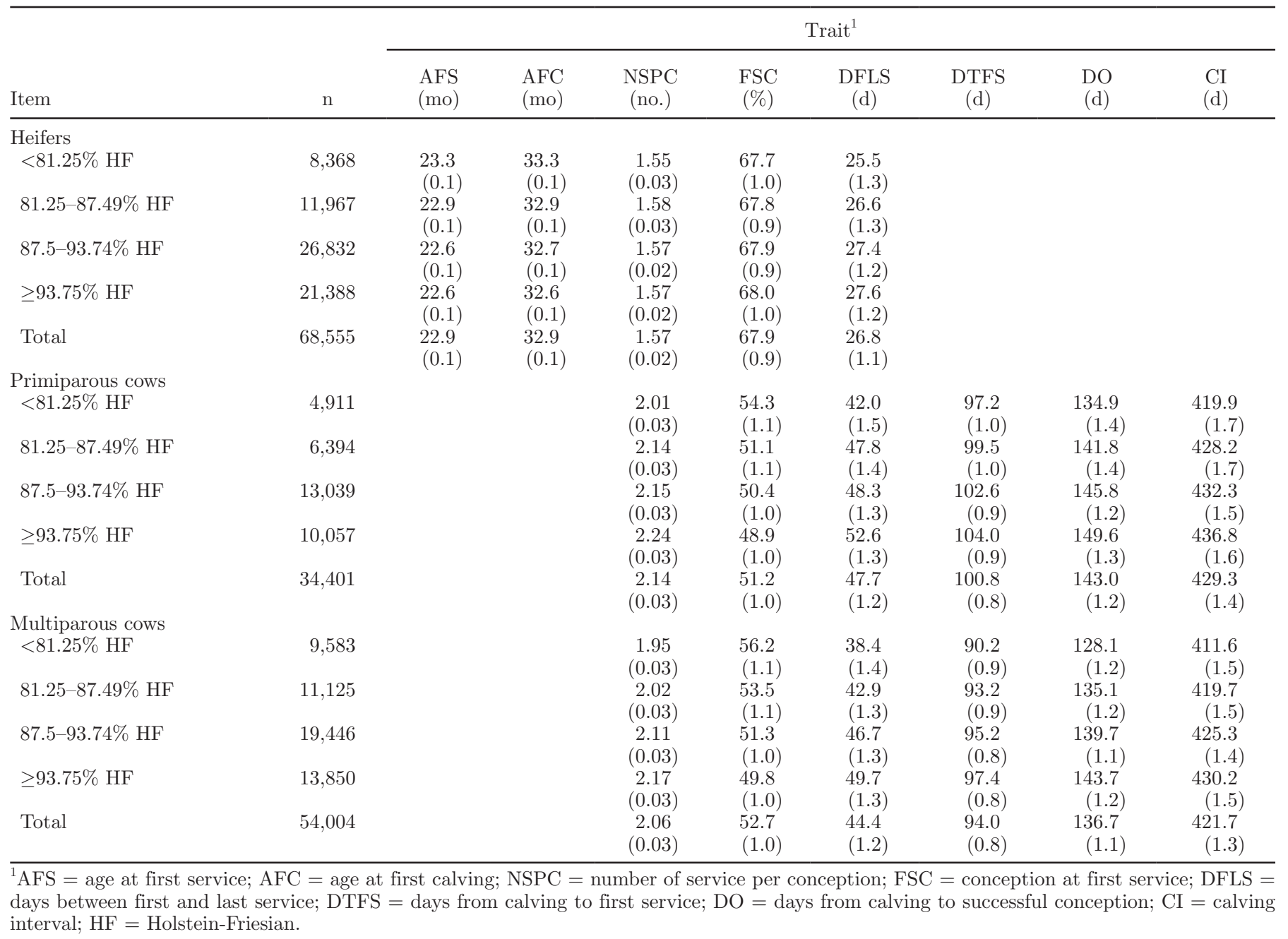

not yet affected by calving and lactation status. The reproductive performance in primiparous cows was inferior compared with multiparous cows. This might be due to the norm of practice of small dairy farmers in Thailand who traditionally raise their female calves, heifers, and pregnant heifers less intensively than cows providing income at the moment. Consequently, these animals are always neglected under improper nutrition management. The results were in agreement with the report of Pongpiachan et al. (2003) and Leelasiri et al. (2006). However, this might be in contrast to results obtained under the normal management protocols in advanced dairy industry countries.

Table 2 shows the posterior means and the $95 \%$ high posterior density intervals of heritabilities and herd contributions for various fertility traits in different parities from univariate analyses. Moderate heritabilities were obtained for AFS (0.26) and AFC (0.28). For
AFS, the heritability estimate was close to a report of Estrada-León et al. (2008) for Brown Swiss (BS) in the tropics of Mexico (0.28) but lower than those reviewed by Lôbo et al. (2000) for tropical dairy cattle $(0.60)$. This value was also higher than the estimates for Canadian Holsteins (Jamrozik et al., 2005), Japanese Holsteins (Abe et al., 2009), Iranian Holsteins (Eghbalsaied, 2011), Dutch Holsteins (de Haer et al., 2013), and Chinese Holsteins (Guo et al., 2014). The result suggested that genetic improvement of AFS could be achieved by selection. The heritabilities for other traits were 0.04 or less, which were lower than previous studies in Canadian Holsteins (Jamrozik et al., 2005) and Japanese Holsteins (Abe et al., 2009) but similar to a report in Thai dairy cattle (König et al., 2005). The heritabilities between 0.01 and 0.04 for cow fertility traits were also found in Cuban Holsteins (Buxadera and Dempfle, 1997), Kenyan Holsteins (Ojango and 
Table 2. Estimates ${ }^{1}$ of heritability and herd contribution for various fertility traits in different parities

\begin{tabular}{|c|c|c|c|c|c|c|c|}
\hline Parameter & Trait $^{2}$ & \multicolumn{2}{|c|}{ Heifers } & \multicolumn{2}{|c|}{ Primiparous cows } & \multicolumn{2}{|c|}{ Multiparous cows } \\
\hline \multirow[t]{4}{*}{ Heritability } & AFS & 0.26 & $0.24,0.28$ & & & & \\
\hline & NSPC & 0.02 & $0.01,0.03$ & 0.03 & $0.01,0.05$ & 0.02 & $0.01,0.04$ \\
\hline & FSC & 0.01 & $0.01,0.02$ & 0.02 & $0.01,0.03$ & 0.02 & $0.01,0.03$ \\
\hline & DFLS & 0.01 & $0.00,0.01$ & 0.02 & $0.01,0.03$ & 0.01 & $0.01,0.02$ \\
\hline \multirow[t]{6}{*}{ Herd contribution } & AFS & 0.38 & $0.37,0.38$ & & & & \\
\hline & $\mathrm{AFC}$ & 0.34 & $0.33,0.34$ & & & & \\
\hline & NSPC & 0.09 & $0.08,0.11$ & 0.11 & $0.09,0.13$ & 0.08 & $0.06,0.09$ \\
\hline & FSC & 0.10 & $0.08,0.11$ & 0.10 & $0.08,0.11$ & 0.08 & $0.06,0.09$ \\
\hline & DFLS & 0.06 & $0.05,0.07$ & 0.07 & $0.05,0.08$ & 0.05 & $0.04,0.05$ \\
\hline & DTFS & & & 0.15 & $0.13,0.16$ & 0.11 & $0.10,0.11$ \\
\hline
\end{tabular}

${ }^{1}$ Means and the $95 \%$ highest posterior density intervals (HPD95) for the posterior distributions.

${ }^{2} \mathrm{AFS}=$ age at first service; $\mathrm{AFC}=$ age at first calving; $\mathrm{NSPC}=$ number of service per conception; FSC $=$ conception at first service; DFLS $=$ days between first and last service; DTFS = days from calving to first service; DO = days from calving to successful conception; CI = calving interval.

Pollott, 2001), Ethiopian dairy cows (Demeke et al., 2004), Mexican BS (Estrada-León et al., 2008; Utrera et al., 2010), and Colombian Holsteins (Zambrano and Echeverri, 2014) under tropical, smallholder conditions. The low heritability in this study suggested that improvement of fertility traits in heifers and cows could be achieved by improving reproductive managements such as successful detection of heat, timely insemination, and feeding practice for growing and postpartum animals. However, the variability among papers was also due to the methodology used.

Herd contributions were always higher than heritabilities in all fertility traits (Table 2), ranging from 0.05 for DFLS, DO, and CI in multiparous cows to 0.38 for AFS in heifers. No reference was found to estimate herd contribution for dairy fertility traits in a tropical environment. Jamrozik et al. (2005) and Abe et al. (2009) reported high estimates of herd contribution for AFS in Holsteins (0.48 and 0.50, respectively). The higher estimate in AFS and AFC could be due to different feeding practices and farmer or breeder decisions on breeding age across herds. Another high herd contribution was 0.15 in DTFS for primiparous cows, which is similar to the reports by Jamrozik et al. (2005), Abe et al. (2009), and Tiezzi et al. (2012). The estimates of herd contribution for NSPC, FSC, DFLS, DO, and CI were low, which implies lower variability of average reproductive efficiency across herd-year class. For FSC, the ratio of variance of service sire to total variance was 0.01 or lower for both heifers and cows (not shown). Very small variance of service sire was reported in an intensive system (Jamrozik et al., 2005; Kuhn and Hutchinson, 2008; Tiezzi et al., 2013). Repeatabilities of fertility traits for multiparous cows (not shown) ranged from 0.10 (DFLS) to 0.17 (DTFS). The estimates were within the range reported for dairy cattle in tropical environment (Ojango and Pollott, 2001; Demeke et al., 2004; Estrada-León et al., 2008).

Table 3 shows genetic correlations estimated among different fertility traits within parity. The estimated genetic correlations were close to 1 for $\mathrm{AFS}$ and $\mathrm{AFC}$, NSPC and DFLS, and DO and CI, and close to -1 for NSPC and FSC, and DFLS and FSC. The results were in agreement with previous studies (Jamrozik et al., 2005; Abe et al., 2009; Eghbalsaied, 2011; Guo et al., 2014). These results suggest that the traits in this study were essentially the same indicator of fertility and may be originally the same in terms of genetic source. Moreover, the FSC and NSPC in both heifers and cows had very high favorable genetic correlations with DO and CI ranged from -0.96 to 0.89 . However, correlation estimates between DO and CI depended on the definition of DO, which is based on subsequent calving, on nonreturn to estrus within $90 \mathrm{~d}$ after last service, or on pregnancy diagnosis. The DO based on nonreturn in estrus or on pregnancy diagnosis could be more interesting, even if possibly less accurate than those based on subsequent calving because it allows an acceleration of at least 6 mo in genetic evaluation of cows, and especially, of AI bulls at their first proofs.

A slight correlation was found between AFS or AFC and NSPC, FSC, and DFLS. This indicated that 
Table 3. Estimates ${ }^{1}$ of genetic correlations (above diagonal) and phenotypic correlations (below diagonal) among fertility traits within different parities

\begin{tabular}{|c|c|c|c|c|c|c|c|}
\hline \multirow[b]{2}{*}{ Parity } & \multirow[b]{2}{*}{ Trait $^{2}$} & \multicolumn{6}{|c|}{ Trait } \\
\hline & & AFS & $\mathrm{AFC}$ & NSPC & FSC & DFLS & \\
\hline \multirow[t]{8}{*}{ Heifer } & AFS & & 1.00 & -0.19 & 0.15 & -0.31 & \\
\hline & $\mathrm{AFC}$ & 0.94 & $(1.00,1.00)$ & $\begin{array}{l}(-0.43,0.04) \\
-0.04\end{array}$ & $\begin{array}{l}(-0.15,0.42) \\
0.12\end{array}$ & $\begin{array}{l}(-0.54,0.05) \\
-0.02\end{array}$ & \\
\hline & & $(0.94,0.94)$ & & $(-0.24,0.22)$ & $(-0.13,0.32)$ & $(-0.32,0.31)$ & \\
\hline & NSPC & 0.26 & -0.08 & & -1.00 & 0.85 & \\
\hline & FSC & $\begin{array}{l}(0.25,0.27) \\
0.06\end{array}$ & $\begin{array}{l}(-0.11,-0.05) \\
-0.25\end{array}$ & -1.00 & $(-1.00,-1.00)$ & $\begin{array}{l}(0.70,0.92) \\
-0.99\end{array}$ & \\
\hline & & $(0.03,0.10)$ & $(-0.26,-0.24)$ & $(-1.00,-0.99)$ & & $(-1.00,-0.32)$ & \\
\hline & DFLS & $(-0.08,-0.05)$ & $\begin{array}{l}0.29 \\
(0.29,0.30)\end{array}$ & $\begin{array}{l}0.73 \\
(0.72,0.75)\end{array}$ & $\begin{array}{l}-0.73 \\
(-0.77,-0.16)\end{array}$ & & \\
\hline & & NSPC & FSC & DFLS & DTFS & DO & $\mathrm{CI}$ \\
\hline \multirow[t]{10}{*}{ Primiparous cows } & NSPC & & -1.00 & 1.00 & 0.58 & 0.87 & 0.89 \\
\hline & FSC & -0.99 & & $\begin{array}{l}(0.99,1.00) \\
-1.00\end{array}$ & $\begin{array}{l}(0.21,0.00) \\
-0.70\end{array}$ & $\begin{array}{l}(0.6(, 0.96) \\
-0.95\end{array}$ & $\begin{array}{l}(0.78,0.98) \\
-0.96\end{array}$ \\
\hline & & $(-0.99,-0.99)$ & & $(-1.00,-0.99)$ & $(-0.91,-0.41)$ & $(-0.99,-0.86)$ & $(-1.00,-0.87)$ \\
\hline & DFLS & 0.81 & -0.70 & & 0.58 & 0.91 & 0.91 \\
\hline & & $(0.80,0.83)$ & $(-0.71,-0.69)$ & & $(0.22,0.81)$ & $(0.83,0.97)$ & $(0.83,0.96)$ \\
\hline & DTFS & -0.09 & 0.07 & -0.09 & & 0.87 & 0.86 \\
\hline & & $(-0.11,-0.08)$ & $(0.05,0.08)$ & $(-0.10,-0.08)$ & & $(0.75,0.96)$ & $(0.73,0.95)$ \\
\hline & DO & 0.69 & -0.75 & 0.83 & 0.48 & & 1.00 \\
\hline & $\mathrm{CI}$ & 0.68 & -0.75 & $\begin{array}{l}(0.83,0.83) \\
0.83\end{array}$ & 0.48 & 1.00 & $(1.00,1.00)$ \\
\hline & & $(0.67,0.70)$ & $(-0.76,-0.74)$ & $(0.82,0.83)$ & $(0.47,0.49)$ & $(1.00,1.00)$ & \\
\hline \multirow[t]{10}{*}{ Multiparous cows } & NSPC & & -1.00 & 0.95 & 0.28 & 0.71 & 0.68 \\
\hline & & & $(-1.00,-1.00)$ & $(0.88,0.98)$ & $(-0.09,0.63)$ & $(0.51,0.86)$ & $(0.48,0.84)$ \\
\hline & FSC & $\begin{array}{l}-1.00 \\
(-1.00,-1.00)\end{array}$ & & $\begin{array}{l}-1.00 \\
(-1.00,-1.00)\end{array}$ & $\begin{array}{l}-0.28 \\
(-0.72,0.11)\end{array}$ & $\begin{array}{l}-0.80 \\
(-0.94,-0.55)\end{array}$ & $\begin{array}{l}-0.78 \\
(-0.73,-0.72)\end{array}$ \\
\hline & DFLS & 0.81 & -1.00 & & 0.72 & 0.94 & 0.92 \\
\hline & & $(0.79,0.82)$ & $(-1.00,-1.00)$ & & $(0.42,0.91)$ & $(0.86,0.98)$ & $(0.81,0.97)$ \\
\hline & DTFS & -0.13 & 0.12 & -0.10 & & 0.93 & 0.94 \\
\hline & DO & $(-0.14,-0.12)$ & $\begin{array}{l}(0.11,0.13) \\
-0.73\end{array}$ & $\begin{array}{l}(-0.11,-0.10) \\
0.83\end{array}$ & & $(0.82,0.98)$ & $(0.85,0.98)$ \\
\hline & & $(0.66,0.69)$ & $(-0.74,-0.72)$ & $\begin{array}{l}0.83 \\
(0.83,0.83)\end{array}$ & $(0.46,0.48)$ & & $(0.99,1.00)$ \\
\hline & $\mathrm{CI}$ & 0.67 & -0.72 & 0.83 & 0.47 & 1.00 & \\
\hline & & $(0.66,0.69)$ & $(-0.73,-0.72)$ & $(0.82,0.83)$ & $(0.46,0.48)$ & $(1.00,1.00)$ & \\
\hline
\end{tabular}

${ }^{1}$ Means (and the $95 \%$ highest posterior density interval in the parentheses) for the posterior distributions.

$\underline{ }{ }^{2} \mathrm{AFS}=$ age at first service; AFC $=$ age at first calving; NSPC $=$ number of service per conception; FSC $=$ conception at first service; DFLS $=$ days between first and last service; $œ$ DTFS = days from calving to first service; DO = days from calving to successful conception; CI $=$ calving interval. 
selection for lower AFS or AFC had little correlated responses to NSPC, FSC, and DFLS in heifers. This is because AFS and AFC often reflect body growth of the heifer rather than its fertility. Therefore, body size of heifers is mainly considered by breeders or farmers when deciding on the right moment for inseminations. Low genetic correlation of AFC with heifer fertility traits was also reported in intensive dairy systems (Jamrozik et al., 2005; Abe et al., 2009). Eghbalsaied (2011) found low to moderate positive genetic correlations in Iranian Holsteins.

The estimated genetic correlations among different fertility traits indicated that selection for cows with high conception rate could lead to shorten DO and CI, as well as DTFS. The FSC and NSPC in both heifers and cows had the highest average of absolute genetic correlations with other traits even though the lowest heritability belonged to this group. Therefore, they could be used as one of the best indicators for heifer or cow fertility and could be complemented by other traits that are genetically considered as different traits such as DTFS and in terms of a fertility index. This would enable efficient selection for better reproductive performance.

Table 4 shows genetic correlations among fertility traits treated as different traits across parities. The highest estimates were obtained between primiparous and multiparous cows, ranging from 0.91 for FSC to 0.99 for DO and CI. The similar results were found for purebred Holsteins in intensive system (Haile-Mariam et al., 2003; Abe et al., 2009) and BS in a mountain climate (Tiezzi et al., 2012). No reports of the genetic correlations in tropical dairy cattle were found. The genetic correlations suggested that fertility measured in subsequent parity can be regarded as the same trait as the first parity.

Genetic correlation between heifers and primiparous cows was high for NSPC (0.83) and FSC (0.81) but not significantly different from zero for DFLS (0.40). For NSPC, the estimated genetic correlation between heifers and primiparous cows was higher than the result for Canadian Holsteins (Jamrozik et al., 2005), German and Austrian Simmental (Gredler et al., 2007), and Italian BS (Tiezzi et al., 2012). For FSC, Abe et al. (2009) reported a genetic correlation of 0.74 between heifers and primiparous cows, whereas the value assessed by Tiezzi et al. (2012) on BS was lower (0.35). For DFLS, a moderate to high genetic correlation between heifers and primiparous cows was reported in Swiss Simmental (0.40, Hodel et al., 1995), Canadian Holsteins (0.72, Jamrozik et al., 2005), German dairy cattle (0.48, Liu et al., 2008), and Italian BS (0.55, Tiezzi et al., 2012).

Genetic correlation between heifers and multiparous cows was 0.68 for NSPC but not significantly different from zero for FSC and DFLS (0.37 and -0.03). The estimates were lowest compared with the estimates for heifers and primiparous cows, and estimates for primiparous and multiparous cows (0.91 and 0.98). These results were different from the study of Tiezzi et al. (2012), which reported that the genetic correlations of the mentioned traits between heifers and multiparous cows were intermediate and positive between estimates for heifers and primiparous cows and primiparous and multiparous cows. However, the estimated genetic correlation between heifers and primiparous cows, as well as primiparous and multiparous cows in the current study showed the same trend as in studies of Roxstrom et al. (2001) and Tiezzi et al. (2012).

Overall, the genetic correlations between heifers and cows fertility were far from 1 . The results suggested that fertility traits in heifers were genetically different from the traits in cows because the animal was not subjected to the same metabolic load during the heifer period as during the lactation period. Therefore, in selection for improvement of heifer and cow fertility

Table 4. Estimates ${ }^{1}$ of genetic correlations among fertility traits treated as different traits across parities

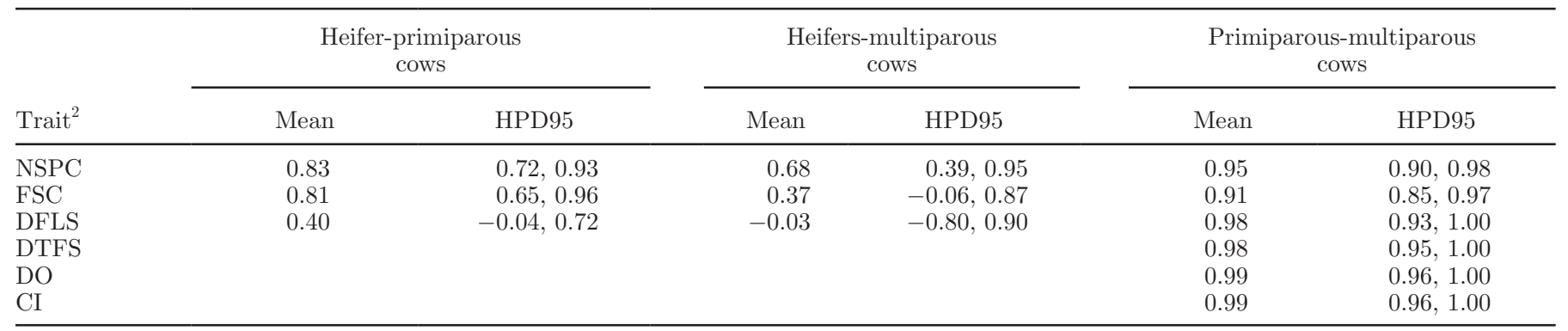

${ }^{1}$ Means and the $95 \%$ highest posterior density intervals (HPD95) for the posterior distributions.

${ }^{2} \mathrm{NSPC}=$ number of service per conception; FSC $=$ conception at first service; DFLS $=$ days between first and last service; DTFS $=$ days from calving to first service; DO = days from calving to successful conception, calving. 
efficiency, it should be analyzed as separate traits in a multiple-trait model for fertility index development.

In conclusion, reproductive efficiency in heifers and cows showed a trend to be lower as HF blood increased. Estimated heritabilities of reproductive traits in heifer and cow were 0.04 or less, only the heritabilities for AFS and AFC were slightly higher, which were similar to the results in the literature. Selection for cows with high conception rate could lead to shortened DO, CI, and DTFS. The FSC and NSPC could be used as the best indicators for heifer/cow fertility and could be complemented by other traits that were genetically considered as different traits such as DTFS and DFLS in terms of a fertility index. This would enable efficient selection for better fertility. Heifer and cow fertility should be considered as different traits in evaluation for genetic improvement. However, virgin heifer traits are measured relatively early in life, and therefore they should be included in tropical dairy cattle breeding program to improve the efficiency of fertility.

\section{ACKNOWLEDGMENTS}

The authors thank the Bureau of Biotechnology for Livestock Production, Department of Livestock Development, for providing the dataset and pedigree file. Special thanks go to Ignacy Misztal and Shogo Tsuruta (Department of Animal and Dairy Science, University of Georgia, Athens) for software technical support and the Agricultural Research Development Agency (Bangkok, Thailand) for financial support.

\section{REFERENCES}

Abe, H., Y. Masuda, and M. Suzuki. 2009. Relationships between reproductive traits of heifers and cows and yield traits for Holsteins in Japan. J. Dairy Sci. 92:4055-4062.

Banos, G., M. P. Coffey, E. Wall, and S. Brotherstone. 2006. Genetic relationship between first-lactation body energy and later-life udder health in dairy cattle. J. Dairy Sci. 89:2222-2232.

Bauman, D. E., and W. B. Currie. 1980. Partitioning of nutrients during pregnancy and lactation: A review of mechanisms involving homeostasis and homeorhesis. J. Dairy Sci. 63:1514-1529.

Buxadera, A. M., and L. Dempfle. 1997. Genetic and environmental factors affecting some reproductive traits of Holstein cows in Cuba. Genet. Sel. Evol. 29:469-482.

de Haer, L. C. M., G. de Jong, and P. J. A. Vessies. 2013. Estimate of genetic parameters of fertility traits, for virgin heifers in the Netherlands. Interbull Bull. 47:143-146.

Demeke, S., F. W. C. Neser, and S. J. Schoeman. 2004. Estimates of genetic parameters for Boran, Friesian and crosses of Friesian and Jersey with the Boran cattle in the tropical highlands of Ethiopia: Reproduction traits. J. Anim. Breed. Genet. 121:57-65.

Department of Livestock Development. 2014. Annual Information dairy farmers 2013. Accessed Jul. 1, 2014. http://ict.dld.go.th/ th2/images/stories/stat_web/yearly/2556/summaryreport/3.report56_milk.pdf. (In Thai).

Eghbalsaied, S. 2011. Estimation of genetic parameters for 13 female fertility indices in Holstein dairy cows. Trop. Anim. Health Prod. 43:811-816.
Estrada-León, R. J., J. G. Magana, and J. C. Segura-Correa. 2008. Genetic parameters for reproductive traits of Brown Swiss cows in the tropics of Mexico. J. Anim. Vet. Adv. 7:124-129.

Gredler, B., C. Fuerst, and J. Solkner. 2007. Analysis of new fertility traits for the joint genetic evaluation in Austria and Germany. Interbull Bull. 37:152-155.

Guo, G., X. Guo, Y. Wang, X. Zhang, S. Zhang, X. Li, L. Liu, W. Shi, T. Usman, X. Wang, L. Du, and Q. Zhang. 2014. Estimation of genetic parameters of fertility traits in Chinese Holstein cattle. Can. J. Anim. Sci. 94:281-285.

Guyomard, H., S. Manceron, and J. L. Peyraud. 2013. Trade in feed grains, animals, and animal products: Current trends, future prospects, and main issues. Anim. Front. 3:14-18.

Haile-Mariam, M., P. J. Bowman, and M. E. Goddard. 2003. Genetic and environmental relationship among calving interval, survival, persistency of milk yield and somatic cell count in dairy cattle. Livest. Prod. Sci. 80:189-200.

Herath, P. S. M. H., and S. Mohammad. 2009. The current status of cattle breeding programmes in Asia. Pages 3-10 in Selection and Breeding of Cattle in Asia: Strategies and Criteria for Improved Breeding. IAEA, Vienna, Austria.

Hodel, F., J. Moll, and N. Kuenzi. 1995. Analysis of fertility in Swiss Simmental cattle: Genetic and environmental effects on female fertility. Livest. Prod. Sci. 41:95-103.

Jamrozik, J., J. Fatehi, G. J. Kistemaker, and L. R. Schaeffer. 2005. Estimates of genetic parameters for Canadian Holstein female reproduction traits. J. Dairy Sci. 88:2199-2208.

König, S., N. Chongkasikit, and H. J. Langholz. 2005. Estimation of variance components for production and fertility traits in Northern Thai dairy cattle to define optimal breeding strategies. Arch. Tierz. 48:233-246.

Kuhn, M. T., and J. L. Hutchinson. 2008. Prediction of dairy bull fertility from field data: Use of multiple services and identification and utilization of factors affecting bull fertility. J. Dairy Sci. 91:2481-2492.

Leelasiri, C., S. Buaban, and J. Sanpote. 2006. Reproductive performance of different dairy cross breeds under smallholder conditions in Thailand. J. Biotec. Livest. Prod. 1:48-56.

Liu, Z., J. Jaitner, F. Reinhardt, E. Pasman, S. Rensing, and R. Reents. 2008. Genetic evaluation of fertility traits of dairy cattle using a multiple-trait animal model. J. Dairy Sci. 91:4333-4343.

Lôbo, R. N. B., F. E. Madalena, and A. R. Vieira. 2000. Average estimates of genetic parameters for beef and dairy cattle in tropical regions. Anim. Breed. Abstr. 68:433-462.

Løvendahl, P., C. Ridder, and N. C. Friggens. 2010. Limits to prediction of energy balance from milk composition measures at individual cow level. J. Dairy Sci. 93:1998-2006.

McDermott, J. J., S. J. Staal, H. A. Freeman, M. Herrero, and J. A. Van de Steeg. 2010. Sustaining intensification of smallholder livestock systems in the tropics. Livest. Sci. 130:95-109.

Meteorological Department. 2013. Annual Weather Summary over Thailand in 2013. Accessed May 10, 2014. http://www.tmd.go.th/ en/climate.php?FileID $=4$.

Office of Agricultural Economics. 2014. Number of Dairy Cattle and Average Fresh Milk Production in Year 2012-2014. Accessed Nov. 1, 2014. http://www.oae.go.th/download/prcai/livestock/milkcow. pdf.

Ojango, J. M., and G. E. Pollott. 2001. Genetics of milk yield and fertility traits in Holstein-Friesian cattle on large-scale Kenyan farms. J. Anim. Sci. 79:1742-1750.

Philipsson, J. 2000. Sustainability of dairy cattle breeding systems utilising artificial insemination in less developed countries-examples of problems and prospects. S. Galal, J. Boyazoglu, and K. Hammond, ed. Pages 551-562 in Developing Breeding Strategies for Lower Input Animal Production Environments. Proc. Workshop, 22-25 September 1999, Bella, Italy. International Committee for Animal Recording (ICAR), Rome, Italy.

Pongpiachan, P., P. Rodtian, and K. Ota. 2003. Reproduction of crossand purebred Friesian cattle in Northern Thailand with special reference to their milk production. Asian-australas. J. Anim. Sci. 16:1093-1101. 
Pryce, J. E., and R. F. Veerkamp. 2001. The incorporation of fertility indices in genetic improvement programs. Pages 223-236 in Fertility in the High-Producing Dairy Cow. M. G. Diskin, ed. Br. Soc. Anim. Sci. Occ. Publ. No. 26. Edinburgh, UK.

Roxstrom, A., E. Strandberg, B. Berglun, U. Emanuelson, and J. Phillipsson. 2001. Genetic and environmental correlations among female fertility traits and milk production in different parities of Swedish Red and White dairy cattle. Acta Agric. Scand. 51:7-14.

Tiezzi, F., C. Maltecca, A. Cecchinato, M. Penasa, and G. Bittante 2012. Genetic parameters for fertility of dairy heifers and cows at different parities and relationships with production traits in first lactation. J. Dairy Sci. 95:7355-7362.

Tiezzi, F., C. Maltecca, A. Cecchinato, M. Penasa, A. Cecchinato, and G. Bittante. 2013. Genetic analysis of dairy bull fertility from field data of Brown Swiss cattle. J. Dairy Sci. 96:7325-7328.
Tsuruta, S., and I. Misztal. 2006. THRGIBBS1F90 for estimation of variance components with threshold and linear models. J. Dairy Sci. 89 (Suppl. 1):15-18.

Utrera, A. R., R. C. C. Robles, J. V. R. Fernandez, and J. L. Lagunes. 2010. Estimation of genetic parameters for fertility traits in Brown Swiss cattle under subtropical conditions of Mexico. Veterinaria (Mex) 41:117-129.

Vaccaro, R., and S. Rivero. 1985. Growth of Holstein Friesian females in the Venezuelan tropics. Anim. Prod. 40:279-285.

Zambrano, J. C., and J. Echeverri. 2014. Genetic and environmental variance and covariance parameters for some reproductive traits of Holstein and Jersey cattle in Antioquia (Colombia). Rev. Bras. Zootec. 43:132-139. 